\title{
Danças Tradicionalistas Riograndenses, Gênero e Memória.
}

\author{
Gisela Reis Biancalana \\ Professora Adjunta - Curso de Dança/UFSM \\ Doutora em Artes/Unicamp - Artes Cênicas \\ Pós Doutoranda de Montfort University - Leicester - UK \\ Membro do Programa de Pós Graduação em Artes Visuais/UFSM
}

\section{Resumo}

O estudo realizou uma imersão em segmentos da cultura riograndense, os Centros de Tradição Gaúcha, focando suas danças tradicionalistas. Este contexto sociocultural foi o mote para uma reflexão sobre as relações de gênero que se estabelecem pela via da memória nas performances estudadas. A abordagem metodológica adotada foi a observação participativa em pesquisa de campo realizada em uma instituição tradicionalista na cidade de Santa Maria/RS. As performances, sob a perspectiva da memória, carregam aspectos das relações de gênero presentes neste contexto sociocultural.

Palavras-chave:

danças tradicionalistas riograndenses, memória, gênero.

\footnotetext{
Abstract

This study carried out an immersion in segments of riograndense culture, Centros de Tradição Gaúcha, focusing their traditionalist dances. This socio-cultural context was the starting point for a reflection on gender relations that is established by memory in these performances studied. The methodological approach adopted was participatory observation in field research in a traditionalist institution in the city of Santa Maria / RS. The performances, from the perspective of memory, bring aspects of gender relations present in this sociocultural context.

Keywords:

riograndense traditionalist dances, memory, gender.
} 
No ano de 1947, aconteceu o Movimento Tradicionalista Gaúcho (MTG) e a fundação do 35 CTG, o primeiro Centro de Tradições Gaúchas (CTG) do estado. Depois dele, vieram inúmeras outras instituições ligadas ao MTG que foram multiplicando-se pelo estado. Hoje existem CTGs em todo Brasil e no exterior contando com milhares de entidades pelo mundo. Segundo Barboza (1996, p. 28), o telurismo gaúcho remonta a meados de 1860, durante a Guerra do Paraguai com o grupo de intelectuais do "Partenon Literário" bem como ao grupo liderado por Cezimbra Jacques. Este sentimento foi reforçado ao longo dos tempos com a instituição do dia do Gaúcho a partir de 1887, com iniciativas do mesmo Major João Cezimbra Jacques e com o aparecimento de entidades isoladas para cultuar a tradição, culminando com o MTG. Para Fagundes (1995, p. 38-42) o MTG foi o primeiro grito de resistência em defesa das tradições gaúchas que realmente repercutiu. Antes disso, o ambiente de guerras e revoluções não se mostrava propício para que tais iniciativas repercutissem. Nesta época, o bombardeio cultural estrangeiro havia alcançado proporções avassaladoras e acabou impulsionando o movimento que alcançou repercussão inédita. Estes fatos, somados à onda romântica tardia no Brasil e no Rio Grande do Sul, no sentido de valorizar as raízes culturais locais, contribuíram para a expansão do movimento.

O afã telúrico aliado à criação destas instituições contribuiu significativamente para recuperação de aspectos da memória resignificados pelas gerações pioneiras e pelas que seguiram. O culto aos elementos reagrupados em releituras possíveis diante da escassez de registros promove mais uma atualização do que uma reprodução Aqui reside a riqueza das atitudes que reconhecem a dinâmica das manifestações culturais, especialmente aquelas marcadas pela efemeridade como aspecto intrínseco ao seu fazer. Empreender a demarcação de territórios ao mesmo tempo em que se assume a sua maleabilidade nas manifestações culturais que se materializam no tempo e no espaço não é tarefa fácil. Para refletir sobre esta dinâmica é preciso pensar, ainda, na memória como um baú de lembranças que, por sua vez, é atravessada por percepções advindas de substratos socioculturais e circunstanciais.

Sendo assim, os dois anos mergulhados na vida do CTG "Piá do Sul" em Santa Maria, no Rio Grande do Sul, oportunizaram a convivência da pesquisadora com o universo investigado e, consequentemente, as trocas com o manancial de memórias que sustentam este trabalho. Esta reflexão escrita objetivou, em meio a abundância de partículas reconhecíveis de tempos vividos outrora, lançar um olhar para seus deslizamentos que circunscrevem relações de gênero potencializadoras de 
devires, por sua vez, atravessados por um passado estendido e agenciado no tempo presente.

Este estudo entende relações de gênero como "a instância onde e por meio da qual os seres humanos aprendem a se converter em e a se reconhecer como homens e mulheres" (MEYER, 1996, p. 44). A memória, por sua vez, é vista pela perspectiva de Henri Bergson, um dos filósofos que aborda a memória na tentativa de superar o dualismo moderno corpo/espírito. Para além das críticas recebidas de autores como Bachelard, por exemplo, vale lembrar algumas colocações de Bergson (1999, p. 266-67) que esclarecem a função da memória. Especialmente, o autor expõe a memória como movimento do tempo e que advém de escolhas úteis.

\footnotetext{
No que concerne à memória, ela tem por função primeira evocar todas as percepções passadas análogas a uma percepçãp presente, recordar-nos o que precede e o que seguiu, sugerindo-nos, assim a decisão mais útil. Mas não é tudo. Ao captar numa intuição única momentos múltiplos da duração, ela nos liberta do movimento de transcorrer das coisas, isto é, do ritmo da necessidade. Quanto mais ela puder condensar esses momentos num único, tanto mais sólida será a apreensão que nos proporcionará da matéria; de sorte que a memória de um ser vivo parece medir antes de tudo a capacidade de sua ação sobre as coisas, e não ser mais do que a repercussão intelectual disto. (266-67)
}

Estas ações enquanto repercussões do intelecto, por sua vez, podem estar relacionadas aos interesses do ser humano ou de uma coletividade. Assim, este passado descortinado pelas investidas relativamente recentes de reatualização foram as maiores ações responsáveis pelo surgimento do MTG enquanto movimento proselítico que defende fervorosamente a tradição gaúcha.

A iniciativa de organizar um Departamento de Tradições Gaúchas (DTG) no grêmio estudantil do ginásio Júlio de Castilhos em Porto Alegre partiu de Paixão Côrtes e outros alunos da escola. A primeira atividade do DTG foi conduzir os restos mortais do general farroupilha, David Canabarro, de Santana do Livramento para Porto Alegre em 1947. Em oito de setembro do mesmo ano, os companheiros resolveram levar ao colégio o fogo simbólico que ficou aceso até vinte de setembro, data da Revolução Farroupilha. Esta foi considerada a primeira ronda crioula que se encerrou com um fandango ambientado tipicamente. Depois desta data, Barbosa Lessa passou a colher assinaturas para a fundação do 35 Centro de Tradições Gaúchas que seria no ano seguinte. Assim, em 1948, foi fundado o 35 CTG contando com 35 membros, exclusivamente homens, em homenagem a data da Revolução 
Farroupilha. De acordo com Paixão Cortes (1975, p. 90), seu lema foi: "Em qualquer chão - sempre gaúcho".

A partir de então, a associação passou a receber cada vez mais sócios e, somente após a segunda diretoria eleita, começaram a surgir as invernadas ${ }^{1}$ campeiras, artísticas, de livros, de divulgação e culturais. As Invernadas Artísticas destas instituições são grupos de canto, música, declamação, trovas e dança. Destaca-se que, até aqui, o movimento era estritamente masculino quando em 1949 as mulheres passaram a ser aceitas. É possível que a entrada das mulheres na associação esteja vinculada, primeiramente, a iniciativa de recuperar antigas danças de salão. Nas apresentações das invernadas artísticas, a dança não era um de seus elementos integrantes e só começaram a aparecer a partir de 1949. As danças hoje praticadas nas entidades tradicionalistas são oriundas das pesquisas realizadas, principalmente, por Paixão Côrtes e Barbosa Lessa, entre outros, no sentido de resgatar e preservar as antigas manifestações coreográficas da cultura riograndense.

Segundo Fagundes (1995, p. 138), outros autores fizeram menções às danças tradicionais do Rio Grande do Sul. Em tempos mais distantes, cronistas que cruzaram a região teceram comentários sobre os bailes e as danças. Alguns musicistas de São Paulo também vieram para pesquisar as músicas das danças, mas não seus aspectos coreográficos. Entre os primeiros gaúchos pesquisadores está o Major João Cezimbra Jacques, com seu Grêmio Gaúcho, de 1898. O Major trouxe idosos para ensinar o sapateio tradicional e preservar as danças do antigo fandango. Paixão Côrtes e Barbosa Lessa receberam a preciosa ajuda de remanescentes desse tempo.

No início de suas atividades, em março de 1949, o 35 CTG foi com sua invernada artística para os festejos comemorativos do Dia da Tradição, em Montevidéu, onde realizaram apresentações diversas, mas não tinham danças para mostrar. Quando voltaram, convidaram as primeiras prendas para estabelecer contato com as coreografias. Ainda no primeiro semestre do mesmo ano, foram procurados por mulheres requisitando sua entrada para o quadro associativo do 35. Esta viagem foi um estímulo para as pesquisas desenvolvidas, posteriormente, por Paixão Côrtes e Barbosa Lessa. Ao fim destas investigações, publicaram os resultados, realizaram conferências e ministraram cursos a fim de divulgar o material conseguido com o objetivo maior de estimular as invernadas artísticas dos CTGs e, consequentemente, o surgimento de grupos de dança tradicionalista. O Manual de Danças Gaúchas, publicado em sua primeira edição no ano de 1957 pelos dois pesquisadores, é até hoje um referencial significativo para os dançarinos e coreógrafos $^{2}$ das invernadas de dança.
1.

Invernada é uma denominação campeira ligada à criação de gado, mas há o sentido figurado atribuído pelo MTG que significa os grupos de atividades desenvolvidas pelos membros das entidades tradicionalistas.
2.

É estranho o uso da palavra coreógrafo para as danças tradicionalistas, que são rigidamente determinadas, mas as evoluções espaciais, bem como algumas poucas variações de passos e sapateios mais livres competem à criatividade de seus coreógrafos. 
Antes de adentrar nas questões próprias da pesquisa o estudo buscou delinear pontos característicos das danças tais como suas origens, seu caráter e alguns de seus aspectos coreográficos. Assim, é importante salientar que a colonização tardia em relação às outras regiões do Brasil, trouxe para o Rio Grande do Sul, danças de origem européia passadas por outras regiões do Brasil, assim como também recebeu influência direta das fontes. Os açorianos contribuíram muito para a formação das danças tradicionalistas seguidos pelos alemães e pelos habitantes das fronteiras. O imigrante italiano contribuiu, mas pouco em relação aos outros imigrantes, uma vez que, logo que chegaram, a Igreja proibia que dançassem. Sua maior contribuição remete-se à música e aos instrumentos por eles fabricados como a viola artesanal e a divulgação da gaita ou acordeon - com sua fabricação no estado.

De acordo com os pesquisadores, de um modo geral, as danças no Rio Grande do Sul desenvolveram-se por dois caminhos diferentes. Um deles é o caminho das danças dramáticas, muitas de caráter religioso e constitui a menor parte das manifestações culturais do estado visto que a sociedade gaúcha é, predominantemente, militar. O outro caminho é o das danças de caráter lúdico, realizadas em festividades cívicas ou comemorações particulares, visando o entretenimento e a socialização. Sendo assim, os autores se voltaram para as danças de salão atribuindo-lhes maior importância tradicional no estado. Para eles, as danças executadas no antigo Fandango são oriundas dos centros de irradiação de modas e transformadas de acordo com as peculiaridades da região. Nas pesquisas realizadas, as danças foram agrupadas pelos autores e denominadas por eles, em um primeiro momento, de gerações coreográficas, terminologia que já não é mais usada atualmente. Assim, neste estudo, optou-se por não utilizar o termo geração por não considerá-lo adequado, uma vez que, a palavra indica época e as origens coreográficas não se remetem apenas a épocas, mas ainda a outros fatores de ordem sociocultural. A palavra geração pode indicar, ainda, descendência, e as danças chegadas ao estado muitas vezes eram oriundas de fontes diversas.

Desta forma, o primeiro tipo de dança que se tem registro no Rio Grande do Sul foi o ciclo dos Fandangos, presente até a primeira metade do século XIX. A palavra fandango no Brasil tem diversos significados ligados a festas e danças. No Rio Grande do Sul pode significar tanto dança masculina sapateada quanto bailes. Estas danças eram de pares soltos e autônomos com partes cantadas e partes instrumentais com sapateados. O segundo tipo de dança sofreu influência do minueto lançado na refinada corte de Luís XIV na França. As coreografias preservavam a separação física, porém, os pares davam-se 
as mãos realizando giros lentos e reverências, sendo coordenados por um mestre de danças. Com a queda da monarquia francesa, o minueto passa a ser considerado como expressão política da nobreza e não se aplicava ao clima de rebeldia reinante. Surgem, então, as contradanças originadas do reel e da contry inglesa. Estas danças eram mais descontraídas e os pares davam-se as mãos ou mesmo os braços e, dependentes entre si, formavam figuras geométricas no salão ainda sob comando de um mestre de danças. O último tipo de dança registrado surge com a queda de Napoleão e o aparecimento das valsas vienenses, danças de pares enlaçados e pares independentes, contra o antigo comando e a frieza das figuras geométricas. Observa-se a progressiva aproximação dos pares, reforçada pela entrada do tango no estado. A introdução dos passos da polca, da Escócia e da Boêmia, resultava em danças vivas e alegres de passos rápidos. Os franceses chamavam a polca de schottisc, porque vinha da Escócia, daí a confusão, no Rio Grande do Sul, entre polca e chote. Assim sendo, as danças praticadas no Rio Grande do Sul eram influências de um dos quatro tipos de dança encontrados ou eram mesclas. Os últimos Fandangos do Rio Grande do Sul, nos fins do século XIX, eram remanescentes das contradanças e das valsas. O sapateado e a viola eram encontrados em raros ambientes rurais.

A partir de então, uma série de fatores tais como os conflitos internos e externos, as influências dos meios de comunicação de massa, a importação de outras culturas dominantes, a falta de iniciativa local, entre outros, fizeram com que o Rio Grande do Sul não oferecesse resistência cultural e se tornasse mais um receptor do que um produtor de cultura e suas danças foram aos poucos sendo esquecidas. Talvez, este tenha sido um dos motivos que fizeram com que iniciativas anteriores ao MTG não frutificassem. No passado, a cultura permanecia viva pela repetição dinâmica que as reatualizava no cotidiano das pessoas. A partir de meados do século $\mathrm{XX}$, iniciou-se o esboço de uma percepção sobre aspectos da cultura riograndense que estavam sendo atravessados intensamente por um processo de esvaziamento desmaterializante. O esforço pela recuperação dos elementos culturais diluídos pelo esquecimento culminou com a erupção do MTG. A preservação das manifestações artístico-culturais do estado passou a ser necessidade de resistência que, aliada ao telurismo riograndense, tornou-se motivo principal da imensurável repercussão do movimento tradicionalista.

Atualmente, as antigas danças praticadas nos fandangos como entretenimento, hoje se transformaram em espetáculo. Nos bailes promovidos pelos CTGs, são dançados os passos das últimas gerações coreográficas com pares enlaçados indepen- 
dentes e, em determinado momento, o baile cessa para apresentação das antigas danças ensaiadas pelo grupo da invernada artística, com uma seriedade ou com a expressão corporal dramaticamente elaborada de acordo com cada proposta de dança. Esta nova organização faz com que a prática das danças tradicionalistas seja cada vez mais exigente. O MTG promove um evento competitivo chamado ENART (Encontro de Arte e Tradição Gaúcha) no qual os dançarinos e as dançarinas das $30 \mathrm{RT}^{3}$ do estado comparecem para competir entre si, determinando quem são os "melhores artistas" do tradicionalismo.

As coreografias presentes nos eventos competitivos são sorteadas quinze minutos antes da apresentação de cada grupo. Cada grupo que se apresenta realiza uma coreografia de entrada, três danças sorteadas entre todas e uma coreografia de saída. São diversas etapas regionais e na etapa final são sorteadas quatro danças. Atualmente, as entradas e saídas também são competitivas numa categoria diferente das danças tradicionalistas e existem coreógrafos especializados para elas. Em 1999, havia duas categorias de competição, as danças tradicionalistas e as entradas e saídas analisadas em conjunto. A partir do ano 2000 passaram a ser três categorias, as danças tradicionalistas, as entradas e as saídas avaliadas separadamente. A progressiva valorização das evoluções coreográficas que arrematam as danças tradicionalistas reflete o atravessamento de intensidades provenientes deste território flexibilizado abrindo espaço para criação.

As danças tradicionalistas gaúchas do Rio Grande do Sul são apresentadas em categorias como as danças sem sapateado, as danças com sapateado e as danças exclusivamente masculinas. As danças apontadas por Paixão Cortes (1994, p. 21) absorveram a memória coletiva fixando o sapateado ibérico, a cortesia francesa, o requebro brasileiro e os passos de polca. Existem outras características fundamentais que, segundo o autor, são indispensáveis para a compreensão do contexto onde surgiram tais danças. Estas características referem-se ao homem, seu "respeito à mulher e sua teatralidade" e se referem à mulher pela sua "retribuição com alegria" (PAIXÃO CORTES, 1994, P.21). O autor discorre muito sobre o homem colocando-o como o dirigente da sociedade, o atuante nas guerras e nas lidas campeiras demonstrando a força destas atividades produtoras daquilo que ele denomina de teatralidade e discorre rapidamente sobre a mulher como ser passivo que se restringe a retribuir seu respeito e admirar suas habilidades.

A escolha pelo enfoque à categoria gênero foi uma opção diante da realidade que se apresentava e se reverbera na dimensão subjetiva das pesquisas sobre arte. Nestas manifestações artístico-culturais, a diferenciação entre os universos
3.

Divisão do estado do Rio Grande do Sul em regiões tradicionalistas. 
masculinos e femininos é reforçada pelos papéis ocupados pelos seus praticantes. Os homens são os peões e realizam movimentos fortes e vigorosos e as mulheres são as prendas que, por sua vez, realizam movimentos mais suaves e delicados, de acordo com os papéis sociais por eles ocupados. Além disto, algumas danças são executadas apenas por peões o que parece refletir diretamente nas relações de gênero que se estabelecem neste universo, bem como nos significados instituídos e instituintes que emergem da temática abordada. O mergulho no contexto sociocultural em questão foi indispensável para a reflexão crítica sobre os aspectos coreográficos que reforçam as relações socioculturais entre os praticantes do tradicionalismo gaúcho. A categoria gênero não existe isolada no respectivo contexto, mas convive e é perpassada por outras categorias formando uma rica cadeia de complexidades que arremessam o passado para o filtro das percepções contemporâneas materializando-as no presente.

Tau Golin (1987, p. 51) é um dos autores mais radicais na crítica ao tradicionalismo gaúcho. Segundo ele, o tradicionalismo é uma cooptação ideológica farsesca, cristalizada e seus praticantes atuam ingenuamente sem qualquer questionamento. Para o autor (1987, p. 54), a cristalização reside nas chamadas "coisas do povo", elaboradas artificialmente, como máscaras da resistência social. Deste modo, o apelo às emoções na prática da tradição seria uma contradição. O conceito de liberdade se direciona para o gaúcho livre que pertence a terra aliada às grandes extensões territoriais dos campos estancieiros. Tau Golin (1987, p. 52) aponta o equívoco mostrando que o gaúcho pertence à terra, porém, a terra não pertence a ele e sim ao latifundiário.

Segundo o autor, visto sob o prisma da perspectiva marxista, os CTGs valorizam as sociedades de classes dominantes e a propriedade privada. Desta maneira, eles reforçam o poder hegemônico simbolizado pela estância através da estrutura proposta pelo MTG. Aqui a figura maior denomina-se "patrão" e vai descendo até chegar ao último degrau da pirâmide constituído pelos "peões". As relações de poder reaparecem em diversas instâncias dentro do tradicionalismo a exemplo dos papéis ocupados por homens e mulheres no referido contexto social. A cada um cabem atividades específicas que reforçam as diferenciações sexuais e, conseqüentemente, as relações de poderes travadas entre dominantes e dominados.

Outro ponto relevante abordado pelo autor diz respeito ao significado etimológico da palavra prenda e da palavra peão. Prenda é o nome, em sentido figurado, atribuído à moça gaúcha, porém, o sentido real da palavra é jóia, relíquia, presente de valor. Neste contexto, observa-se claramente de que 
modo o conceito de mulher é trabalhado aqui, como um adorno ou como algo que se possui. A postura em questão revela a ideologia hierárquica do papel do homem em relação ao da mulher. Peão em sentido figurado é o homem associado a uma entidade tradicionalista gaúcha, porém, o significado original da palavra é do homem ajustado ao trabalho rural ou empregado para condução de tropa. Observa-se que o nome atribuído ao homem é oriundo das lidas campeiras conferindo-lhe o status de provedor, aquele que trabalha na terra e dela tira o sustento (TAU GOLIN, 1987, p. 57-60). Assim, a partir do nome de batismo dos tradicionalistas também seria possivel detectar o pensamento do autor sobre esta estrutura refletindo-se na ideologia dos interesses de setores dominantes não apenas no que se refere à categoria gênero como também à classe social.

Este estudo pretendeu, a princípio, enfocar a mulher e o homem nas práticas de danças tradicionalistas riograndenses, ou seja, as diferenças sexuais detectadas nestes contextos relacionadas à perspectiva da memória. O ponto inicial de observação da pesquisa foi o estudo dos papéis sociais exercidos por prendas e peões no tradicionalismo, bem como, o estudo das danças praticadas nestes universos. Neste sentido, existem pontos de contato entre o olhar distanciado e as referências que motivaram este trabalho, o contexto sociocultural em questão e a perspectiva de Tau Golin formando um caldo denso de conjecturas.

Sendo assim, a primeira vista provoca o olhar distanciado que foca a dinâmica da dominação masculina vestida pelo manto da cultura riograndense e reatualizada pelo MTG em diversas de suas organizações culturais inclusive nas danças. Deve-se considerar, também, que este contexto social foi reatualizado com base na história de lutas políticas e no universo do trabalho desenvolvido nestes contextos. Acrescenta-se, ainda, que a recuperação da memória cultural foi realizada por pontos de vista masculinos circunscrevendo territórios de desejos que pulsam pela veia do passado atravessada pelo presente. Por outro lado, estes desejos são instáveis pelo próprio atravessamento do tempo e desencadeiam fluxos de memórias outras que deslizam para novos territórios. O novo revela-se pela dinâmica da cultura reatualizada separando os momentos nos quais são retomadas as danças do passado e os momentos onde se abre espaço para as propostas de renovação que acontecem, atualmente, nos eventos promovidos por esta entidade. Esta separação assume o passado enquanto passado, quase como uma afirmação e reconhecimento de que hoje as coisas não exatamente como antes. Como disse Bergson (1999) as ações realizadas pela via da memória são movimentos do tempo o que mostra a cultura como matéria viva, dinâmica, em constante transformação. 
No que se refere à postura de Tau Golin, acredita-se que a crítica do autor seja, em parte, pertinente, uma vez que o tradicionalismo não foi uma cultura espontânea e sim recriada e organizada formalmente com fins específicos. Porém, esta recriação e repercussão emergem de desejos latentes em erupção. Sendo assim, a visão marxista do autor supracitado, algumas vezes, parece bilateral reforçando a presença do que é certo ou errado, do dominante e do dominado, não visualizando a multiplicidade de sentidos para a enorme disseminação do movimento. O seu radicalismo acaba por impedi-lo de enxergar aspectos positivos na cultura. A vivência em campo proporcionou um contato onde foram travadas relações de respeito, amizade e admiração e onde as dimensões sensíveis e intelectuais tinham o mesmo peso. Esta situação revela o passado materializado na cultura gaúcha se estendendo como parte integrante do presente, mas entendido como matéria reatualizada. Portanto, não quer representar e sim reorganizar as partículas do tempo que continuam pulsando. A repetição das práticas de danças tradicionalistas riograndenses, com suas entradas e saídas, são rupturas no cotidiano nos CTGs e nos eventos das entidades a fim de fazer com que o passado permaneça, mas se resignifica no presente e movimenta um substrato cultural que inevitavelmente é instável. 
BARBOSA LESSA e PAIXÃO CÔRTES. Danças e Andanças da Tradição Gaúcha. RS: Garatuja, 1975, p. 103.

BARBOZA, M. C.. Aspectos de Folclore Tradição Cultura do Rio Grande do Sul. Passo Fundo/R.S.: Pe. Berthier, 1996, p. 28.

BERGSON, Henri. Matéria e Memória ensaio sobre a relação do corpo com o espírito. São Paulo: Martins Fontes, 1999.

FAGUNDES, A. A..Curso de Tradicionalismo Gaúcho. Porto Alegre/ RS: Martins Livreiro-Editor, 1995.

GOLIN, Tau. Por Baixo do Poncho. RS: Tchê, 1987.

PAIXÃO CÔRTES e BARBOSA LESSA. Manual de Danças Gaúchas. SP e RJ: Irmaõs Vitale, 1955.

PAIXÃO CÔRTES. Danças Tradicionais Riograndenses - Achegas. Passo Fundo/ RS: Pe. Berthier, 1994.

SCOTT, Joan. Gênero: uma categoria útil de análise histórica. In: Educação \& Realidade. Porto Alegre/RS: UFRGS, v. 16, nº 2, 1990. MEYER, D. E.. Do Poder do Gênero: uma articulação teóricoanalítica. In: Gênero \& Saúde (orgs. Marta Júlia Marques e outros), Porto Alegre/RS: Artes Médicas, 1996. 